DOI 10.37882/2223-2982.2020.11.04

\title{
О НОВОМ ПОДХОДЕ К ИЗУЧЕНИЮ ПРОСТРАНСТВА МЕСТНЫХ ТОВАРНЫХ РЫНКОВ РОССИЙСКОЙ ИМПЕРИИ ВТОРОЙ ПОЛОВИНЫ ХІХ В. (ПО МАТЕРИАЛАМ ТУЛЬСКОЙ ГУБЕРНИИ)
}

\section{ABOUT A NEW APPROACH TO STUDYING THE SPACE OF LOCAL COMMODITY MARKETS OF THE RUSSIAN EMPIRE OF THE SECOND HALF OF THE XIX CENTURY (ON THE MATERIALS OF THE TULA PROVINCE)}

\section{N. Bilenko}

Summary: The article is devoted to the analysis of the results of using a new approach to studying the boundaries and spatial organization of local commodity markets of the Russian Empire in the second half of the 19th century, based on materials from the Tula province. With the help of digital analysis of mass historical sources (documents of fiscal and administrative accounting) - «Journals of general verification of trade and industrial establishments», stable trade relations between manufacturers, traders and consumers are analyzed. As a result of using the new approach, the features of the spatial organization of trade and market relations in the province were established: first, an almost complete coincidence of the administrative and economic boundaries of the province was revealed; secondly, a multi-level system of the local commodity market of the Tula province of the second half of the 19th century was established, which included a set of local markets.

Keywords: all-Russian market, economic space, city, mass historical sources, post-reform Russia.

\author{
Биленко Никита Алексеевич \\ К.и.н., доцент, Тульский государственный \\ педагогический университет им. Л.Н. Толстого
}

nikitabilenko@mail.ru

Аннотация: Статья посвящена анализу результатов использования нового подхода к изучению границ и пространственной организации местных товарных рынков Российской империи второй половины XIX В., реализованного на основе материалов Тульской губернии. С помощью цифрового анализа массовых исторических источников (документов фискально-административного учета) - «Журналов генеральной поверки торговли и промышленных заведений» анализируются устойчивые торговые связи между производителями, торговцами и потребителями. В результате использования нового подхода были установлены особенности пространственной организации торгово-рыночных отношений в губернии: во-первых, выявлено практически полное совпадение административных и экономических границ провинции; во-вторых, установлена многоуровневая система местного товарного рынка Тульской губернии второй половины XIX в., включавшая совокупность локальных рынков.

Ключевые слова: всероссийский рынок, экономическое пространство, город, массовые исторические источники, пореформенная Россия.
И зучение всероссийского рынка имеет давнюю историографическую традицию, причем многоаспектность предмета исторического исследования обусловила наличие целого комплекса проблем, неоднократно находившихся в центре внимания историков, экономистов, социологов и культурологов. Одной из них является проблема пространственной организации торгово-рыночных отношений в Российской империи второй половины XIX В., для решения которой историками предлагалось множество подходов. В частности, масштабность предмета исследования побудила многих ученых рассматривать всероссийский рынок в качестве совокупности местных. Подобная схема еще в 1980-х гг. была использована в исследовании Б.Н. Миронова, где внутренний рынок империи предстал в качестве совокупности взаимосвязанных местных рынков, объединенных общей функцией - «осуществлением товарообмена между производителями и потребителями В масштабе всей страны» $[25$, с. 5-6]. В рамках данного подхода в последние десятилетия было проведено множество региональных исследований, которые, правда, касались процесса функционирования и развития ряда отраслевых рынков (в первую очередь - зерновых) [1; $5 ; 21 ; 23 ; 24 ; 27 ; 28 ; 29]$. Подобная используемая историками модель изучения, несомненно, способствует детализации знаний в области рыночных отношений и географии торговых связей в России, однако одновременно затрудняет рассмотрение всероссийского рынка (или даже местных) в качестве единого экономического пространства, в пределах которого обращается не только хлебный товар. Разрешение данного противоречия, вероятно, следует искать в междисциплинарных исследованиях.

С точки зрения ученых-экономистов местные (региональные или как их иногда именуют в исследованиях - локальные) товарные рынки представляют собой автономные единицы, условно выделенные на основе тер- 
риториального классификационного критерия [4; 30, с. 151]. При этом методологическую основу их выделения в рамках национальных рынков составляет теория воспроизводства, согласно которой местный (региональный или локальный) рынок является экономическим пространством, где на основе местных ресурсов производятся товары, предназначенные для удовлетворения местного спроса, посредством местной торговой сети $[2,22,26]$. Обнаружению данной воспроизводственной основы должно способствовать выявление устойчивых торговых связей между производителями, торговцами и потребителями, а география этих связей, соответственно - обнаружению пространственных конфигураций местных товарных рынков империи. Для этих целей историками традиционно используется множество различных исторических источников, но наиболее подходящими, на наш взгляд, могут стать документы фискально-административного учета - «Журналы генеральной поверки торговли и промышленных заведений» [3]. Эти массовые источники содержат описания каждого промышленного и торгового предприятия губернии, в частности, сведения о местах, откуда были привезены товары или где было приобретено сырье для последующей переработки или реализации. Типовая структура данных документов, сохранявшаяся на протяжении всей второй половины XIX в. позволила автоматизировать обработку большого массива сведений путем создания источнико-ориентированной реляционной машиночитаемой базы данных (в нашем случае - на основе СУБД Microsoft Access).

В результате анализа материалов «Журналов генеральной поверки торговли и промышленных заведений» по Тульской губернии за 1880-е гг. [6, л. 166-180; 7, л. $2-100 ; 8$, л. 57-81; 9, л. 9-35; 10, л. 2-78; 11, л. 12-30; 12, л. $3-35 ; 13$, л. 1-111; 14, л. 9-36; 15, л. 1-175; 16, л. 3-104; 17, л. 9-29; 18, л. 3-35; 19, л. 6-28; 20, л. 9-47], последующей формализации их сведений для составления базы данных и формирования автоматизированных запросов, было установлено, что абсолютное большинство предприятий во всех городах Тульской губернии получало сырье от местных торговцев. Так, в 1880-х гг. 100\% промышленных заведений (фабрик, заводов, ремесленных мастерских) уездных городов Одоева и Богородица получали сырье из стационарных торговых предприятий, а также с базаров и ярмарок соответствующих населенных пунктов. В Венёве подобных заведений было $86 \%$, в Белёве $-85 \%$, в Туле $-84 \%$, в Кашире $-80 \%$, в Епифани - 76\%, в Новосили - 75\%, в Ефремове - 72\%, в Черни - 67\%, в Алексине - 60\%. Небольшая часть предприятий обрабатывающей промышленности получала продукты для переработки из соседних промышленных заведений. Так, например, 6\% фабрик, заводов и ремесленных мастерских Белёва приобретало полуфабрикаты из промышленных заведений самого города, в Крапивне таких насчитывалось около 9\%. Почти пятая часть промышленных заведений городов Тульской губернии заку- пала сырье у производителей в соответствующих уездах: 20\% предприятий Алексина - в Алексинском уезде, 22\% ефремовских - в Ефремовском, 24\% епифанских - в Епифанском, 25\% чернских - в Чернском, 50\% крапивенских - в Крапивенском. Таким образом, в пространственном отношении устойчивые торговые связи между большинством производителей и поставщиками сырья ограничивались пределами города и соответствующего уезда.

Однако в городах, расположенных недалеко от крупных промышленных или торговых центров, через которые пролегали транспортные артерии (торговые дороги, губернские шоссе, речные пути сообщения), промышленные предприятия закупали сырье в относительно отдаленных районах. К примеру, в Алексине $20 \%$ предприятий получали сырье из приграничной Калужской губернии (из Жиздренского уезда по р. Оке к Алексину сплавляли строевой и дровяной лес). В Кашире 20\% заведений закупало продукты (особенно фрукты для производства уксуса) в Серпухове. В Венёве - 15\% из Ельца, в Новосили - 12,5\% из Орла. Особое значение при этом играла удаленность уездных городов от этих торговых центров, которая редко превышала 50 верст. Наибольшим разнообразием отличалась география источников сырья промышленных заведений губернского центра Тулы (самого развитого в промышленном и торговом отношении города провинции). География местностей, откуда поступало сырье для промышленных предприятий Тулы, представлена в Диаграмме № 1.

Анализ пространства местного товарного рынка предусматривает так же выявление устойчивых связей между непосредственными производителями и торговцами. Сведения «Журналов генеральной поверки торговли и промышленных заведений» свидетельствуют о том, что большинство торговых предприятий в городах провинции было ориентировано на перепродажу товаров народного потребления. Так, в Белёве в 68\% торговых заведений перепродавались продукты, которые привозились в города сельскими перекупщиками (прасолами), а также самими крестьянами в базарные и ярмарочные дни. Аналогичная ситуация наблюдается и в других населенных пунктах губернии: в Туле и Одоеве - 67\%, в Епифани - 51\%, в Ефремове - 47\%, в Кашире и Черни - 46\%, в Крапивне - 45\%, в Венёве - 43\%, в Богородицке $-40 \%$, в Новосили - $31 \%$. Стоит отметить, что во всех уездных городах располагались торговые заведения, в которых реализовывались товары, поступившие из губернского центра. Например, на полках 35\% крапивенских торговых заведений можно было обнаружить тульские товары; в Венёве - в 32\%, в Новосили - в 31\%, в Черни - в 29\%, в Епифани - в 24\%, в Алексине и Богородицке - в 23\%. Наименьшая доля тульских товаров в ассортименте торговых точек обнаруживается в Ефремове - в 9\% (что связано со значительной удаленностью города от губернского центра и наличием Орлово-Грязской железной дороги), в Белёве - в 8\% (втором по вели- 
Долевое распределение промышленных предприятий города Тулы второй половины XIX в. по регионам - поставщикам сырья

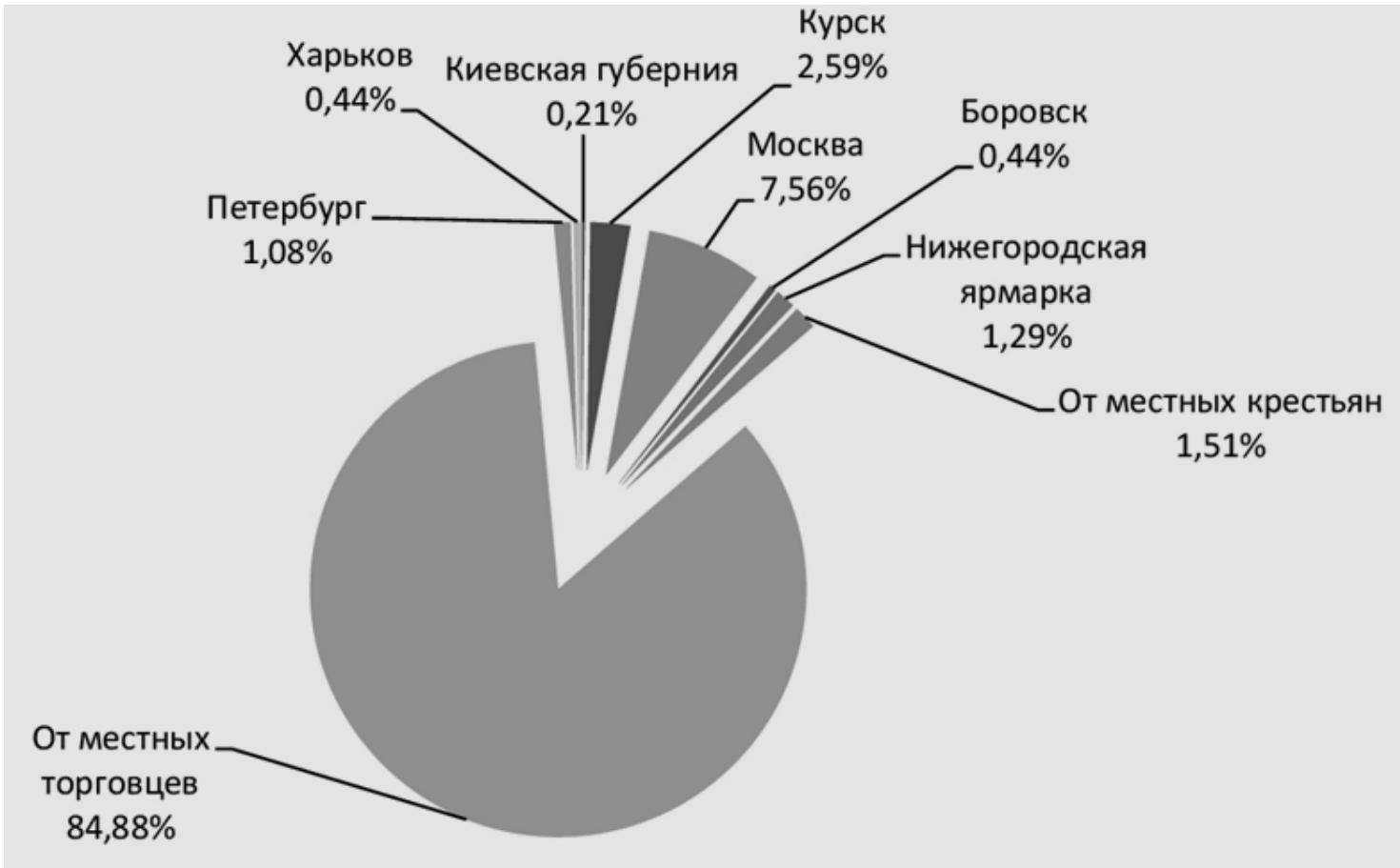

чине городе Тульской губернии, обладавшем пристанью на р. Оке) и Кашире - в 4\% (наиболее приближенном в Москве населенном пункте провинции).

Наряду с товарами из губернского центра в магазинах, лавках, ларях и рундуках присутствовали товары из столицы. Очевидно, что наибольшая доля московских товаров обнаруживается в населенных пунктах северных уездов Тульской губернии, а также в уездных городах, имевших доступ к железнодорожным магистралям. Так, в Кашире доля торговых заведений, где продавались товары из Москвы была выше 27\%, в Богородицке - 25\%, в Ефремове - 18\%, в Венёве - 17\%, в Белёве - 11\%. Наименьшее количество торговых точек, реализовывавших московские товары фиксируется в южных городах чернозёмной полосы провинции - в Черни (4\%) и Новосили (9\%), что, несомненно, связано с их существенной удаленностью от столицы и отсутствием крупных путей сообщения. Существенно, что на полки торговых заведений уездных городов в большинстве случаев попадали товары из Москвы, которые не производились на территории Тульской губернии: предметы роскоши, «колониальный товар», канцелярские принадлежности.

Рассматривая пространственную организацию торгово-рыночных отношений в Тульской губернии, было бы ошибочно предполагать абсолютную экономическую замкнутость провинции. Во многих торговых заведениях уездных городов, значительно удаленных от губернского центра, а также расположенных на судоходной р. Оке и имевших доступ к шоссейным дорогам, фиксируется наличие товаров из самых отдаленных районов империи. Так, в алексинских торговых заведениях можно было обнаружить товары из Ельца, Ефремова, Калуги, Серпухова, Царицына; в Белёве - из Болхова, Калуги, Киева, Орла, Нижнего Новгорода. Несомненно, наибольшим ассортиментом товаров располагал губернский город Тула - из Варшавы, Петербурга, Пинска, Калуги, Харькова, Курска, Серпухова, Москвы, Ярославля, Нижнего Новгорода (см. Диаграмму № 2). Однако, несмотря на это, большинство торговых предприятий всех городов Тульской губернии в основном реализовывали товары местного производства.

Анализ пространства местного товарного рынка был бы неполным без выявления взаимосвязей городских и сельских торгово-промышленных предприятий. При детальном рассмотрении материалов источников по Тульской губернии было установлено, что в большинстве сельских стационарных торговых точек продавались товары из ближайших уездных городов. Так, в 95\% стационарных торговых заведений Тульского уезда реализовывались товары из губернского центра, в 83\% лавок и ларей ефремовского уезда - из Ефремова, в 82\% венёвских - из Венёва. Аналогично выглядела ситуация в остальных местностях Тульской губернии: в Епифанском уезде подобных заведений насчитывалось до 77\%, в Новосильском - 64\%, в Белёвском - 62\%, в Чернском - 55\%, в Каширском - 53\%. Множество лавок в уездах Тульской губернии реализовывали товары, поступавшие напря- 
Долевое распределение торговых заведений города Тулы второй половины XIX века по регионам - источникам реализуемых товаров

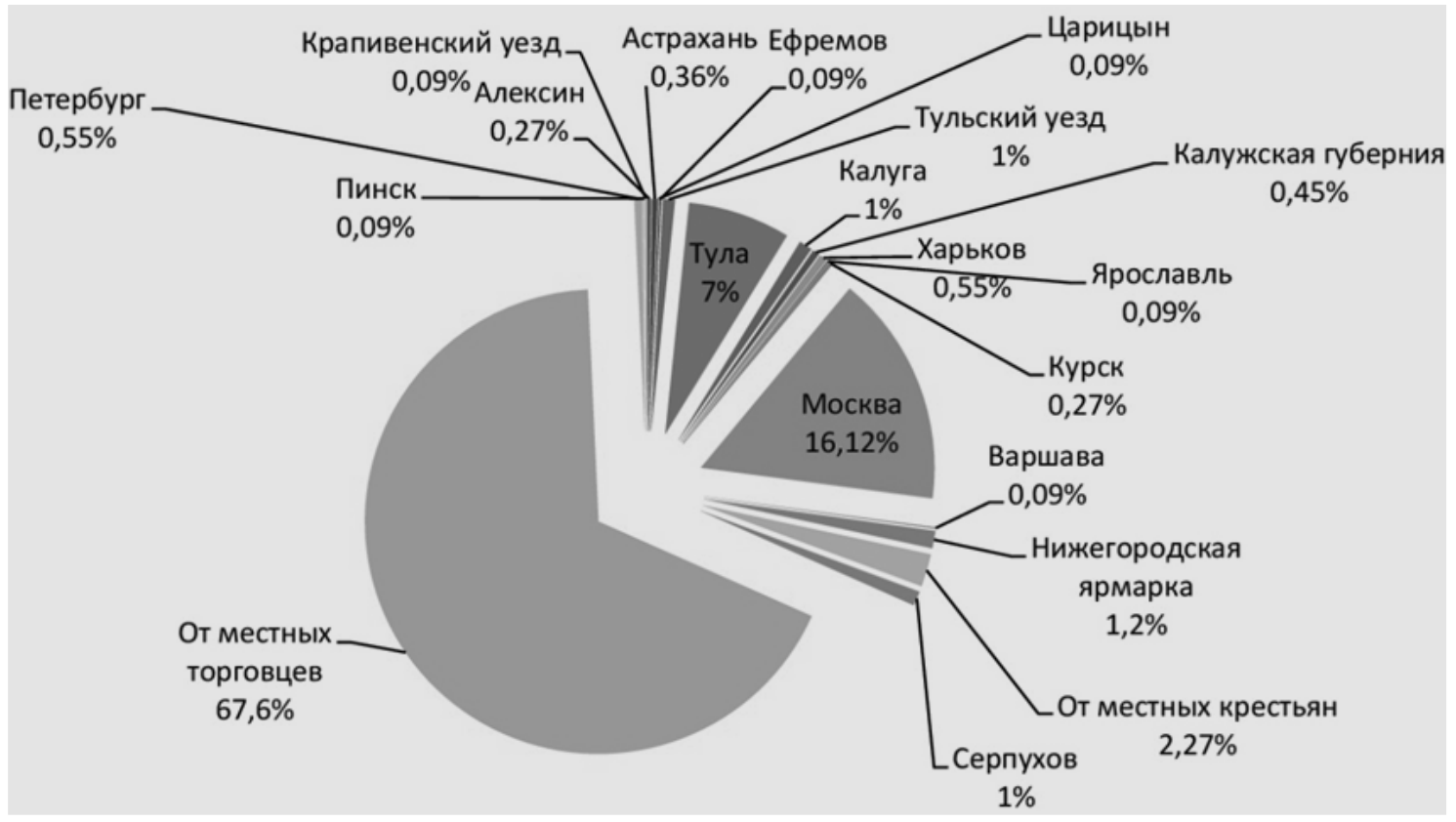

мую из Тулы. Например, в Алексинском уезде таковых торговых заведений было около 28\%, в Богородицком - 24\%. В остальных местностях провинции товары из губернского центра первоначально оседали в уездных городах, а уже затем продолжали движение в деревню.

Таким образом, формализация сведений массовых исторических источников - «Журналов генеральной поверки торговли и промышленных заведений» и последующий количественный анализ полученных сведений позволил выявить устойчивые торговые связи между субъектами рыночных отношений. В свою очередь, проведенный анализ географии этих связей между поставщиками сырья и производителями товаров, между производителями и розничными торговцами позволяет констатировать наличие воспроизводственной основы, сложившейся в пределах Тульской губернии. Иными словами, в провинции существовало местное производство, ориентированное на удовлетворение местного спроса при помощи местной торговой сети. При этом большая часть торгово-промышленных заведений обеспечивала производство товаров, их обращение и потребление в пределах небольших территорий, которые зачастую совпадали с административными границами уездов. В связи с этим, во-первых, возможно зафиксировать наличие полусамостоятельной хозяйственной системы - местного товарного рынка Тульской губернии, а во-вторых, представить местный рынок в качестве многоуровневой системы, состоявшей из совокупности локальных рынков, включавших в себя территорию городов и соответствующих уездов (см.: Картосхему № 1).
В этом случае своеобразным экономическим центром местного товарного рынка Тульской губернии можно считать губернский город, который выполнял функции регионального производственного и распределительного центра. Отсюда товары поступали в уездные города, которые затем оказывались в уездах посредством системы ярмарок, базаров или стационарных торговых заведений. Уездные же города выполняли функции точек концентрации сырьевых ресурсов и продуктов кустарной промышленности, поступавших с территорий уездов.

Вместе с тем, местный товарный рынок не являлся полностью автономным. Выявленная география устойчивых торговых связей заключалась в условном квадрате: Орел - Калуга - Серпухов - Зарайск - Елец. Следует отметить, что экономическое пространство довольно редко совпадает с географическим. По мнению историка Ю.П. Бокарева, экономическое пространство «возникает на основе географического размещения ресурсов, надстраиваясь над ним в форме виртуального пространства» [4, с. 84]. Тем не менее, экономическое пространство рассматриваемого местного товарного рынка во второй половине XIX в. в большей степени совпадало с административными (географическими) границами Тульской губернии, что во многом было обусловлено влиянием институциональной системы и инфраструктурных элементов рынка [31]. Подобное совпадение не следует считать исключением, так вся экономика Российской империи того времени была пронизана властными отношениями, в связи с чем «административная 
Картосхема № 1

Пространство местного товарного рынка Тульской губернии во второй половине XIX века

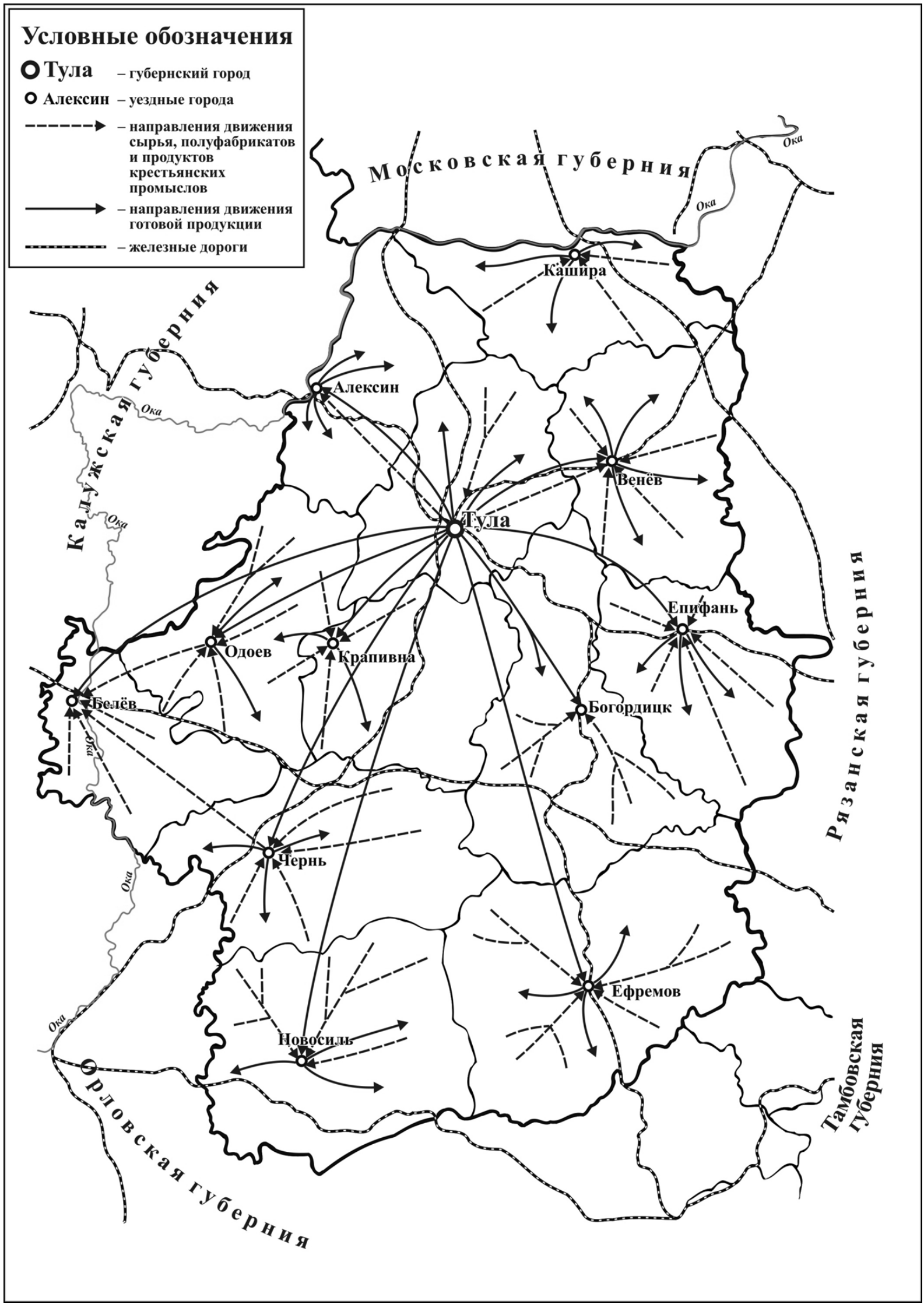


принадлежность региона во многом определяла его экономическую структуру» [4, с. 82].

Предлагаемое использование массовых исторических источников и описанный механизм их анализа по- зволяет географически зафиксировать основную массу сделок купли-продажи товаров, имевших место во второй половине XIX в. в России, и при этом не исключает возможности выявления таковых в рамках чаще изучаемых отраслевых товарных рынков.

\section{ЛИТЕРАТУРА}

1. Алиев Э.Г. Формирование основ «национально-окраинных рынков» в структуре всероссийского рынка (на примере Азербайджана: 1810 - 1917 гг.): дис. ... д-ра экон. наук: 08.00.03. М., 1999. 332 с.

2. Бернвальд А.Р. Региональные проблемы товарного обращения (в районах Сибири и Дальнего Востока). Новосибирск: Наука, 1984. 209 с.

3. Биленко Н.А. Журналы генеральной поверки торговли и промышленных заведений как исторические источники по изучению внутреннего рынка Российской империи второй половины XIX века // Современная наука: актуальные проблемы теории и практики. Серия: Гуманитарные науки. 2018. № 1. C. 4-9.

4. Бокарев Ю.П. Региональное экономическое пространство России: вопросы теории и исторической практики // Уральский исторический вестник. 2014. № 4 (45). С. 82-92.

5. Гальских Е.В. Текстильный рынок Западной Сибири во второй половине XIX в.: дис. ... канд. ист. наук: 07.00.02. Барнаул, 1995. 208 с.

6. Государственное учреждение «Государственный архив Тульской области» (далее - ГУ ГАТО). Ф. 118. Оп. 1. Т. 9. Д. 19338.

7. ГУ ГАТО. Ф. 118. ОП. 1. Т. Я. Д. 20315.

8. ГУ ГАТО. Ф. 118. ОП. 1. Т. 9. Д. 20316.

9. ГУ ГАТО. Ф. 118. ОП. 1. Т. 9. Д. 20318.

10. ГУ ГАТО. Ф. 118. ОП. 1. Т. 9. Д. 20319.

11. ГУ ГАТО. Ф. 118. ОП. 1. Т. 9. Д. 20320.

12. ГУ ГАТО. Ф. 118. ОП. 1. Т. 9. Д. 20322.

13. ГУ ГАТО. Ф. 118. ОП. 1. Т. 9. Д. 20323.

14. ГУ ГАТО. Ф. 118. ОП. 1. Т. 9. Д. 20324.

15. ГУ ГАТО. Ф. 118. ОП. 1. Т. 9. Д. 20325.

16. ГУ ГАТО. Ф. 118. ОП. 1. Т. 9. Д. 20326.

17. ГУ ГАТО. Ф. 118. ОП. 1. Т. 9. Д. 20327.

18. ГУ ГАТО. Ф. 118. ОП. 1. Т. 9. Д. 20328.

19. ГУ ГАТО. Ф. 118. ОП. 1. Т. 9. Д. 20329.

20. ГУ ГАТО. Ф. 118. ОП. 1. Т. 9. Д. 20331.

21. Давыдов М.А. Всероссийский рынок в конце XIX - начале XX в. и железнодорожная статистика. СПб.: Алетейя, 2010. 832 с.

22. Дворядкина Е.Б. Локальный потребительский рынок товаров и услуг: теоретические аспекты исследования // Известия Уральского государственного экономического университета. 2011. № 6 (38). С. 98-104.

23. Ивонин А.Р. Структура регионального рынка дореформенной Западной Сибири (вторая половина XVIII - начало XX в.) // Современное историческое сибиреведение XVII - XX в.: сб. науч. тр. / под ред. Ю.М. Гончарова. Барнаул, 2005. С. 128-142.

24. Мизис Ю.А. Формирование рынка Центрального Черноземья во второй половине XVII - первой половине XVIII вв.: дис. ... д-ра. ист. наук: 07.00 .02$. Тамбов, 2006. 815 с.

25. Миронов Б.Н. Внутренний рынок России во второй половине XVIII - первой половине XIX в. Л.: Наука, 1981. 259 с.

26. Новоселов А.С. Теория региональных рынков. Новосибирск: Сиб. соглашение; Ростов н/Д: Феникс, 2002. 446 с.

27. Роднов М.И. Пространство хлебного рынка (Уфимская губерния в конце XIX - начале XX вв.). Уфа: [б. и.], 2012. 225 с.

28. Суслина С.А. Региональный зерновой рынок Сибири в 1900-1917 г. (по материалам Томской губернии): дис. ... канд. ист. наук: 07.00.02. Барнаул, 2002. $200 \mathrm{c}$.

29. Тагирова Н.Ф. Рынок Поволжья (вторая половина XIX - начало XX вв.). М.: 000 «Издат. центр науч. и учеб. Программ», 1999. 309 с. (Научные доклады; вып. 89).

30. Феоктистова Н.А. Фрагментация экономического пространства и формирование локального рынка // Актуальные вопросы современной науки. Сборник научных трудов. № 6. Вып. 2. Новосибирск: [б. и.], 2009. С. 151-158.

31. Bilenko N.A. Trade legislation of the Russian Empire and the problem of local commodity markets' borders of the Tula governorate in the second half of the nineteenth century // The Economic History Society Programme including New Researchers' Papers \& Abstracts of the other Academic Papers. Keele: Keele University, 2018. P. 146-150.

(c) Биленко Никита Алексеевич (nikitabilenko@mail.ru). 